\title{
How Servant Leadership Principles Affect Employee Turnover at a Solid Waste Management Firm
}

\author{
Clifton Thacker \\ Liberty University \\ Gene Sullivan \\ Liberty University \\ Stanley Self \\ Purdue University Global
}

The authors examine servant leadership and employee turnover at a solid waste management (SWM)

firm, including extensive review of literature pertaining to leadership, servant leadership, and SWM. Multiple interviews were held with personnel at an SWM firm that utilizes servant leadership to gain a better understanding of the experiences of these employees. The study indicates that servant leadership has a positive impact on employee satisfaction and, consequently decreases turnover. Servant leadership was found to affect the lives of the participants. The authors developed multiple themes based on data analysis, including: culture, accountability, support, and commitment.

\section{INTRODUCTION}

Homes and businesses generate solid waste and recyclable materials. Numerous organizations retrieve the trash and recyclables with equipment designed to minimize environmental impact and maximize operational efficiency. Private waste firms, unlike public sector entities, must recruit and retain customers in a highly competitive market. The organization with the most effective price, product mix, and emphasis on service will have an advantage. Waste and recycling firms that employ servant leadership principles may provide the differentiation necessary to better compete in the market (Sekerka \& Stimel, 2014).

\section{Background of the Problem}

Leadership skills are necessary for success. Management increasingly incorporates servant leadership; a servant-leader is a servant first. That philosophy begins with the attitude that leaders must serve others first (Otero-Neira, Varela-Neira, \& Bande, 2016). Servant leadership is hierarchically horizontal, rather than vertical, differing in its primary emphasis on others in comparison to other managerial styles focused on the leader (Williams, Brandon, Hayek, Haden, \& Atinc, 2017). A servant leader first considerer the concerns of stakeholders, including employees and executive leadership, prior to satisfying personal needs. 
SWM firms that incorporate servant leadership aspects within their operational and management philosophies will fundamentally alter the way they operate. A company-wide implementation of servant leadership principles will permeate all levels of the business, from the executive level to the truck driver, emphasizing the needs of others first. The growth experienced from a change in philosophy to servant leadership will assist in identifying both the needs of the employees, as well as those of the current and potential customers (Barbuto \& Wheeler, 2006).

\section{Problem Statement}

The general problem was a lack of understanding of the impact of servant leadership principles on employee turnover in the solid waste industry. The specific problem to be explored is the impact of servant leadership on turnover within a nationwide SWM firm. Dutta and Khatrii (2017) linked servant leadership traits with employee turnover intentions through positive organizational behavior attributes, but stated that there is a pronounced dearth of focused research in the literature. Kashyap and Rangnekar (2016) identified extant literature positively connecting servant leadership with employer branding, but could not directly associate servant leadership with current and potential employees in a firm that emphasized branding.

The recruitment of capable operational employees is critical; it is considerably more efficient to keep quality employees than to hire, train, and acclimate a new hire of the same quality (Mertel \& Brill, 2015). The servant leadership principles of teamwork and community would allow SWM firms and their operations to engage their followers and subordinates in the planning and decision-making processes involved (Yigit, \& Bozkurt, 2017). For operational staff in particular, the cost to replace an existing driver may surpass $\$ 10,000$ due to driver shortages and that more than one recruit will likely be recruited in an effort to find a stable replacement for the outgoing driver (Sersland \& Nataraajan, 2015). The goal of SWM firms is to collect trash and recyclables quickly, often yielding a less-qualified workforce (Baylor, 2016).

\section{Purpose Statement}

The purpose of this qualitative case study was to comprehend the impact of servant leadership on employee retention within a leading national waste company and to explore the perceptions of servant leadership through key leaders within a leading SWM firm. The results of this study may motivate other leading SWM firms to employ servant leadership principles in their organizations in order to better retain quality personnel and reduce employee turnover.

The focus of this study was to determine if a servant leadership style would be effective in employee retention within the SWM industry. A servant leadership framework focused on effective management and ethical responsibility is currently relevant as businesses strive to find a societal advantage in their respective sectors (Krog \& Govender, 2015). Greenleaf (1977) stated, "Businesses are asked not only to produce better goods and services, but to become greater social assets as institutions" (p. 147).

\section{CONCEPTUAL FRAMEWORK}

The conceptual framework of this study, centered on the impact of servant leadership is derived from other existing leadership theories that bound and support Greenleaf's (1977) definitions of servant leadership. Contemporary theories of servant leadership include Maslow's 1954 hierarchy of needs, Hersey and Blanchard's 1982 situational leadership model, Herzberg's 1974 two-factor or motivationhygiene model, and Graen's and Uhl-Bien's 1995 leader-member exchange (LMX) theory. All of these general leadership theories possess qualities that compliment or underlie servant leadership principles.

\section{Discussion of Relationships between Concepts}

A core belief of servant leadership is the community impact of the business itself. Successful businesses not only generate goods and services that allow for the business and its employees to flourish, but also create a positive societal impact in their respective communities (Greenleaf, 1977). Maslow 
(1998) commented how jobs at all levels of an organization, when a hierarchically common goal is endorsed by all, can gradually lead to a higher sense of social accomplishment both for the company and for the individual. Within the chain of command, a servant leader sees him or herself within the hierarchical pyramid, not on top (Boone \& Makhani, 2012). Guitierrez-Wirsching, Mayfield, Mayfield, and Wang (2015) suggested focusing on the bottom of the pyramid to achieve sustainability through servant leadership. The encouragement and facilitation of societal behaviors through macro leadership principles within an organization creates a more positive attitude with employees within their employment and externally in the community (Searle \& Barbuto, 2013). The societal impact a private waste company can have, via an implementation of servant leadership philosophies, can positively transform the firm, their employees, and the communities they service.

\section{Summary of the Conceptual Framework}

Servant leadership considers people first; it shares selected characteristics and traits with other leadership theories. According to Greenleaf (1977), firms develop personnel with servant leadership principles that are people-centered. Barbuto and Wheeler (2006) listed other theories with similar precepts as servant leadership, such as LMX theory and transformational leadership. Nasidi, Kamarudeen, and Bahaudin (2015) identified a firm's basic needs fulfillment for employees and contributions to greater causes, specifically in the waste industry, increases commitment to the leader and to the firm as a whole. Servant leadership's unique principles of putting others first, along with the shared ideals from other similar leadership theories, would have a dramatic impact within a solid waste and recycling firm,

\section{SIGNIFICANCE OF THE STUDY AND LITERATURE REVIEW}

The study will add to the growing works of literature signifying the increased importance of servant leadership within organizations. Particularly, SWM companies form a critical component of communities where consumer and commercial waste needs must be addressed in an ever-increasing environmentally friendly fashion. Lapointe and Vandenberghe (2018) found that servant leaders influence the relational bond between employees and their firm, providing a positive environment that creates a sense of obligation by the employee to the firm and a keen awareness of the costs of leaving the organization. Private SWM firms employing servant leadership principles in their operations may gain an advantage over their competitors by retaining valuable employees and reducing the soft and hard costs of attrition.

\section{A Review of the Professional and Academic Literature}

This study attempted to align servant leadership principles with SWM operations and employee retention. The servant leadership model is based on Greenleaf (1977) who outlined the principles of servant leadership. SWM and SWM operations have many differing adaptations (Ghiani, Lagana, Manni, Musmanno, \& Vigo 2014; Jalil, Grant, Nicholson, \& Deutz, 2016; Kirakozian, 2016), but the concepts of servant leadership integrated within an entire firm would have a profound impact on all aspects of an organization, including retention. Leadership, servant leadership, elements of servant leadership, other leadership and supporting theories, foundations of SWM, and employees are all reviewed in determining whether or not servant leadership principles has an impact on employee turnover at an SWM firm.

\section{Servant Leadership}

Greenleaf (1977) stated that a leader is a servant first. Servant leaders refrain from utilizing their given power as a means of accomplishing tasks. Rather, the use of interpersonal communication and persuasion is exercised primarily to better understand their followers' needs (Mehembe \& Engelbrecht, 2014). The actions a servant leader are coupled with the self-concept of who a servant leader is (Sendjaya, Sarros, \& Santora, 2008). Lacroix and Verdorfer (2017) identify servant leaders as positive role models. Looking towards the future, servant leaders seek to embolden their followers to provide a constructive and helpful contribution to their organizations (Yigit \& Bozkurt, 2017). 
Servant leadership is one of the more popular leadership theories being undertaken by companies today. Contrary to other leadership theories, servant leaders are characterized by their willingness to follow first, adhere to organizational requirements next, and satisfy their own demands last (Jit et al., 2016). Barbuto and Wheeler (2006) posited servant leadership is closely aligned with transformational leadership, including service, trust, and vision, but differs when considering the alignment between the motives of the leader and follower. A horizontal focus on followers, rather than a typical vertical leaderfocused perspective, makes servant leadership unique amongst all other leadership styles (Williams et al., 2017).

Servant leadership has become appealing to millennials, with characteristics including frequent and frank performance reviews, a desire to develop a friendship with their superiors, and an insistence on levels of support and personal interests not found in many other leadership theories (Barbuto \& Gotfredson, 2016). Servant leadership goes well beyond a management style, incorporating a unique set of attitudes that must be developed by leaders who elect to adopt servant leadership principles (Boone $\&$ Makhani, 2012). The deliberate choice of leaders who desire to service others first through servant leadership creates a passion and desire for leadership (Akbari, Kashani, Nikookar, \& Ghaemi 2014).

\section{Elements of Servant Leadership}

Servant leadership contains many characteristics that are depicted differently by various scholars. Krog and Govender (2015) focused on Barbuto and Wheeler's (2006) five servant leadership dimensions within the servant leadership questionnaire (SLQ) of altruistic calling, wisdom, organizational stewardship, emotional healing, and persuasive mapping when emphasizing the effect of employee empowerment through servant leadership on project management. Barbuto and Wheeler listed the following eleven potential aspects of servant leadership: Calling, listening, empathy, healing, awareness, persuasion, conceptualization, foresight, stewardship, growth, and community building.

\section{Foundations of SWM}

SWM is an important industry and is crucial to the infrastructure of rural counties, cities, states, and countries. SWM requires multi-level management, including maintenance, sales, accounting, and operations. The adoption of SWM programs requires interaction between customers and employees, which is normally controlled by an operations division within the SWM organization. According to Vault (2019),

Few industries are as critical to humankind as waste management, with every person impacted by it. According to the Environmental Protection Agency (EPA), the country's waste industry successfully managed 254 million tons of household and other municipal solid waste in 2013 , with the average person throwing away 4.4 pounds of garbage every day. (para. 3)

\section{Operations}

Operational waste collection counts for over $40 \%$ of the entire cost of MSW expenditures (Jaunich et al., 2016). de Souza Melare, Gonzalez, Faceli, and Casadei (2017) identified operational support systems for SWM, including radio-frequency identification (RFID), geographic information systems (GIS), and global positioning systems (GPS); all are designed to monitor solid waste and recycling equipment and containers. SWM is comprised of various tactical, strategic, and operational choices, incorporating solid waste treatment options, treatment facility sites, capacity and expansion capabilities, the flow of waste and recyclables to treatment sites, operational service, waste and recyclable collection days, commercial fleet procurement and allocation, and the routing of all collection vehicles (Ghiani et al., 2014).

\section{Costs of SWM Employee Turnover}

Employee turnover in SWM has expensive and dangerous consequences, specifically within operations. The necessity of consistently retrieving MSW and recyclables from customers often prompts 
an expedited hiring process when turnover occurs, frequently bypassing safety training or causing an imbalance in employee pay (Baylor, 2016). DeWeese (1999) stated numerous for-hire carriers encounter employee turnover rates near 100\% annually. Employee turnover and industry-wide driver scarcity has prompted the use of autonomous equipment at some landfills (Greenwalt, 2017).

\section{General Costs of Employee Turnover}

Employers are focusing increasingly on Human Resource departments to help combat the negative outcomes of employee turnover. Wang, Wang, $\mathrm{Xu}$, and Ji (2014) stated employee turnover is one of the most serious risks that can threaten stability within a firm due to external and internal factors. High turnover rates negatively impact organizational productivity, efficiency, and aspects of manufacturing through both direct costs, such as remuneration, and indirect costs, such as lowered morale, among remaining employees (Zeng \& Honig, 2016). The cost of employee turnover, including losing an employee and recruiting their replacement, averages nearly $20 \%$ per employee and routinely exceeds $100 \%$ of yearly compensation for each job lost when accounting for the loss of customer revenue and human capital (Spencer, Gevrek, Chambers, \& Bowden, 2016). Flint, Haley, and McNally (2013) found a newly hired employee receives an average of 15 days of new employee training in particular firms; it takes eight to sixteen weeks to become competent in their jobs.

Recent studies have reaffirmed and emphasized the critical role intangible benefits play in reducing turnover. Firms should examine their company procedures concerning organizational and interpersonal justice to assess how their employees are treated and evaluated by both the company and management in an effort to reduce turnover (Flint et al., 2013). The use of pressure tactics by management within a firm are often correlated with employee turnover, with last-second appeals by managers who employ a pressure approach to retain personnel rendered ineffective (Reina, Rogers, Peterson, Byron \& Hom, 2018). According to Shuck, Twyford, Reio, and Shuck. (2014), employees who feel support in their development and receive encouragement towards their career goals within a firm have additional advancement opportunities and are less likely to leave their employer.

\section{Summary of the Literature Review}

Servant leadership is a leadership philosophy gaining traction in management circles as a way of keeping and rewarding quality employees. It shares some traits with other classic and contemporary leadership theories and incorporates many distinctive principles of its own. The unique aspect of servant leadership that differentiates it from other leadership theories is the emphasis on the elevated status of followers and the servant mindset of the leaders. Listening and empathy are emphasized as key traits within servant leadership, making servant leadership increasingly distinctive from other leadership theories. The act of listening, with an openness and acceptance of empathy, is the key characteristic of effective management (Jit, Sharma, \& Kawatra, 2016). An SWM firm that chooses to integrate a servant leadership archetype, which includes listening and empathy, will likely experience increased employee satisfaction and, consequently, decreased employee turnover and separation.

SWM is a mature and stable industry that exists in every town, city, and state, and is impacted by every human and business; little has been documented as to what the direct influence and cost of employee recruitment, retention, and replacement is within SWM firms. Turnover and separation in SWM are extraordinarily costly, presenting challenges to organizations to be more efficient in retaining quality employees (Mertel \& Brill, 2015). The concepts that underlie SWM and their operational personnel are both complicated and expensive to supervise, requiring a distinctive combination of management, leadership concepts, and competent employees. Implementation of servant leadership principles companywide may assist not only in recruiting and retaining employees, but also in training existing leaders to serve those employees that directly handle both company initiatives and customer requirements.

Employee turnover has disastrous effects on firms, not only counting the direct costs with hiring, training, and replacing the former employees, but also the indirect costs of added workload to remaining employees, squandered productivity, lost human capital, and potential customer attrition. Effective retention strategies involve an amalgamation of intangible and tangible benefits. Intangible benefits such 
as training and development can achieve higher levels of employee engagement, thereby reducing turnover (Shuck et al., 2014). Each firm has their own guidelines on how to recruit, retain, and replace employees, exclusive not only to the organization but often in their industry, as well. SWM firms have the unique task of recruiting qualified operational employees, including commercial drivers, which has become increasingly difficult due to scarcity. The onus is on SWM companies to not only recruit and adequately train competent personnel, but to retain them as well through an exceptional balance of tangible and intangible benefits. Servant leadership offers a backdrop for SWM firms to provide this needed balance through an emphasis on followers and a servant mindset for the leaders.

\section{THE STUDY}

The study examines the role servant leadership as experienced a solid waste management (SWM) company and the impact it has had on employee retention. The SWM corporation was a significant competitor among waste management firms in the United States in 2011 (Fickes, 2011). The SWM industry encounters significant personnel turnover; the cost to replace a single departed driver and train a new driver often exceeded $\$ 10,000$ in 2015 (Sersland \& Nataraajan, 2015). If the research demonstrates a proclivity of increased employee retention through servant leadership principles, then other SWM and driver-centered businesses may stand to benefit by incorporating a similar servant leadership approach.

The researcher organized the project in a qualitative manner to explore the situational, interpretive, and experiential characteristics often found in qualitative studies (Stake, 2010). Additionally, this would help clarify the impact of servant leadership at the researched SWM firm.

\section{Participants}

The researcher contacted a senior level of management at the firm being researched for a list of potential research participants. The senior manager agreed to distribute, via company email, a recruitment letter generated by the researcher to all employees of the researched firm with company email addresses. The senior manager and the potential research participants were informed that their involvement in the study was completely voluntary.

The researcher initially used both cellular and electronic means of communication with the survey participants. After an employee agreed to participate in the study, the researcher then primarily used cellular communications to establish a positive, direct, and valuable working relationship with the research participant. Harvey (2017) classified the researcher-participant relationship as a working alliance, requiring conscious, unconscious, and preconscious levels between the two parties. All participants who contributed to the study were informed of the confidentiality concerning their responses. The researcher followed all moral and ethical guidelines in collecting the data.

\section{Research Method and Design}

The researcher used a qualitative method for the research. Qualitative methods allow for the acquisition of knowledge from a relatively small sample size. Qualitative research is used to explore a problem or issue (Cresswell \& Poth, 2018). Data representing personal experiences in unique situations can be gathered using qualitative data (Stake, 2010). The researcher relied on feedback and opinions from the participants during interviews as the main sources of information.

A single case study design was used for the research. Through exploration of the available literature, only one SWM firm was identified as using servant leadership principles as an organization. Case studies allow researchers to examine the meanings of situations, conveying to others the complexities contained in the research (Stake, 2010). According to Creswell and Poth (2018), researchers use a single case study design when examining an entire program to illustrate a specific issue. One reason for the use of a single case study design would be if the circumstances of the research represent an unusual case, diverging from industry norms (Yin, 2014). Case studies usually involve more variables of interest than specific data points and use several sources of evidence, requiring the data to converge into a unique fashion (Tsang, 2014). 


\section{Research Question}

How do servant leadership principles impact employees and their employers within SWM firms?

Employee turnover can be an impediment in all industries. Turnover diminishes the effectiveness of a firm, negatively impacting the productivity rate and weakening the morale of current employees within the business (Devi \& Krishna, 2016). Hancock, Allen, Bosco, McDaniel, and Pierce (2013) defined turnover as an antecedent to unwanted outcomes, such as the loss of human and social capital along with operational disruption, which burdens the remaining employees with training and getting to know newcomers and tasks management with recruitment and other overhead expenditures. Turnover also leads to inadequate customer service, decreased profits and revenue, increased accident rates, and lower output (Hausknecht, 2017).

\section{Population and Sampling}

The population of the research included current employees at an SWM firm, which is the subject of the case study. The SWM company has hundreds of branches scattered across North America. Each location has a group of employees that perform the specific tasks the branch is responsible for handling, which may include commercial and residential waste removal, recycling, and waste processing, or a variation of the aforementioned operational duties. The sampling populous included those employees who chose to respond to the recruitment letter submitted by the researcher.

A random, purposeful sampling strategy was used to select the participants. Creswell and Poth (2018) identified random purposeful sampling as a way to collect data an add credibility when the potential sample size is too great. Current employees of the SWM firm were considered for the research. All employees must have had a minimum full-time tenure with the company of at least six months, giving the employee an opportunity to not only observe the impact of servant leadership within the organization, but also in comparison to any alternate leadership strategies used by previous employers he or she may have had.

According to O'Reilly and Parker (2012), qualitative research is focused with the richness of the data gathered, so the number of research subjects within a sample is contingent upon the nature of the particular topic and the available resources. Van Rijnsoever (2017) stated data collection and analysis within qualitative research should persist until no new concepts or codes exist, demonstrating saturation.

The sample size was eight participants, demonstrating an effective saturation point for a qualitative single case study focused on the experiences of the research subjects. Through interview questions, the saturation point may lie between six and twelve interviews; though, it may also be less (Creswell \& Poth, 2018). Interviews with participants continued until a saturation point was reached. After the saturation point within coding and data themes is reached, the data should be capable of producing a degree of generalization (Boddy, 2016). Qualitative research measures the adequacy of sample size by the depth of data, requiring samples sufficient to best characterize the topic being researched, but not too great in size as to become repetitious and oversaturated (O’Reilly \& Parker, 2012).

\section{Summary of Data Collection}

Data were initially collected through interviews of participants via phone calls. Each call was recorded, digitalized into a file, and then transcribed. The transcribed data were entered into a qualitative analysis computer program, 'NVivo,' which generated codes and themes to create new research data. The researcher kept paper logs as well, as a supplement and backup to the digital files. All files, digital and non-digital, were created with complete confidentiality, using numbers as identifiers (i.e., Participant 1) to differentiate between the interviews. Finally, all data were securely stored. Digital data in passwordprotected files on a password-protected computer hard drive, and paper logs in a locked cabinet in the researcher's office. 


\section{Summary of Data Analysis}

The researcher compiled all of the data collected from participant interviews and inputted the data into 'NVivo' qualitative data analysis software to examine. Basic coding was also entered into 'NVivo' by the researcher, with the understanding that the data would likely produce additional codes through the software not considered previously. After analysis, the original and new codes were interpreted and triangulated for authenticity. The finished data were interpreted for emergent themes that emanated from the research.

\section{Summary of Reliability and Validity}

To ensure the reliability of the case study, the researcher formulated an interview guide to maintain consistency within the interview segment. The data were then collected and the files analyzed within the concepts outlined in the study, which include the literature review, the research questions, and the conceptual framework. The researcher also used a triangulation strategy to substantiate the data accumulated during the study, producing thick and rich descriptions of the researched matter. After a saturation point was reached during the research process, the interviews were concluded and the summaries of the data were prepared.

\section{APPLICATION TO PROFESSIONAL PRACTICE AND IMPLICATIONS FOR CHANGE}

\section{Overview of the Study}

This study seeks to determine what impact servant leadership had on a SWM firm and their employee retention efforts. SWM firms are service-oriented and labor-intensive, necessitating the continuous efforts of recruitment and retention. It is considerably more efficient to keep quality employees than to hire, train, and acclimate a new hire of the same quality (Mertel \& Brill, 2015). Servant leadership may provide a method that helps in both hiring and maintaining quality personnel in a service-driven industry. The actions a servant leader takes coupled with the self-concept of who a servant leader is lead to not only performing a unique service but, more importantly, to being a dedicated servant (Sendjaya et al., 2008).

The responses from the interview participants were consistent in several ways: putting others first, describing a positive work culture, a team-first mentality, and an overwhelming desire to stay with their current employer. The participants who were hired by the SWM firm described the immediate training undertaken by the firm to train servant leaders. Those who joined the firm through acquisition spoke of the lengthy, costly, and necessary managerial overhaul it took to become servant leaders. The primary research question for the study involved how servant leadership principles impact employee turnover rates at SWM firms, and the findings of the interviews provided relevant information to address the research question.

\section{Anticipated Themes/Perceptions}

Based on previous findings, the researcher anticipated a positive reaction from the interview participants concerning the SWM firm's incorporation of servant leadership. Given the selfless underpinnings intertwined within servant leadership principles, the researcher predicted a positive correlation between improved employee relations and employee retention within firms that practice servant leadership. The researcher also estimated an optimistic response from participants when asked if the principles of servant leadership would influence them to either stay or leave for another company that did not employ servant leadership within that firm.

\section{Presentation of the Findings}

The researcher complied findings for the study through themes that originated from multiple interviews with various personnel of the selected SWM firm. The participants who were interviewed at the SWM firm were employed in different locations and in various positions across North America. The themes that emerged from the interviews aligned with various aspects of the literature reviewed in preparation for the study and were further analyzed with data analysis software. The conceptual 
framework helped to foster ideas for the study, and the resulting themes supported answers for the primary research question.

The conceptual framework for this study was developed through extensive research on the principles of leadership, servant leadership in particular, and the SWM industry. The concepts within leadership include economic, political, and organizational structure accomplishments that rely on the efficient and successful guidance by their leaders (Parris \& Peachey, 2013). Servant leadership has proven to be an effective leadership model; successful firms not only generate services that allow for the business and its employees to flourish, but also create a positive societal impact in their respective communities (Greenleaf, 1977). Servant leadership may be a successful leadership model to follow in the SWM industry. There are numerous stakeholders outside of private firms involved in operating SWM, including public managers of municipalities, business owners, and regulatory agencies (de Souza et al., 2017).

The findings of the study dovetail with the conceptual framework outlined earlier in the paper. The participants in the study frequently mentioned terms positively associated with the effective servant leadership demonstrated in their firm; expressions such as caring, freer, and autonomy were used in describing how the participants viewed leadership. A prerequisite of participation in the study was having at least one former employer to gauge the servant leadership model against. Several of the interviewees had previously worked for other SWM firms that did not incorporate a servant leadership philosophy; those participants used expressions such as "making a difference" and "could be myself" to describe the difference between their current SWM employer and former employer SWM firms. The findings indicated a preference for servant leadership among the employees in the SWM firm in the study. These findings may have implications for other SWM firms.

The foundation for this study is significant due to the evolving need for leadership domestically and internationally for efficient SWM practices. Recruitment of talent in the SWM is difficult in general, as waste professionals must deal with the collection of leftovers, refuse, and other unwanted elements from customers (Sekerka \& Stimel, 2014). As economies strengthen and environmental regulations tighten, the need for effective SWM programs to handle the additional waste generated by citizens becomes more important (Wilson \& Velis, 2014). The literature on leadership demonstrated many successful theories and strategies implemented by businesses. Servant leadership, in particular, offered unique principles that stood out amongst other prevailing leadership theories; specifically, the core notion that a leader not only serves, but serves others first (Greenleaf, 1977). The study then focused in the influence servant leadership may have on not only serving customers at an SWM firm, but in recruiting and retaining valuable employees to carry out the principles involved in incorporating servant leadership.

Previous studies from authors such as Antunes and Franco (2016), Lacey and Kennett-Hensel (2015), Otero-Neira et al. (2016), Mahembe and Engelbrecht (2014), and Chan and Mak (2013) addressed general leadership attributes such as authenticity, trust, work team environments, and emotion that foster positive employee-employer relations. The findings of this study reinforce the previous leadership studies outlined in this paper, with qualities like caring and value being repeated often throughout the interview. Further, several of the participants specifically used the term "team" to describe their work environment, with all employees, regardless of their individual position within the SWM firm, working together as one to complete tasks.

One leadership topic researched for this study that was not made evident by the participants was storytelling. According to Auvinen, Lämsä, Sintonen and Takala (2013), storytelling is a function whereby leaders communicate stories, anecdotes, refrains, and memories that become part of the narrative within firms. The researcher surmised this might be, in part, due to the acquisition trend of their firm, which was brought up by several participants. Acquisitions typically involve a purchase of all or most assets from another firm, ceasing operations at the old business, and an often-chaotic transition of personnel. The researcher theorized the case study SWM firm might incorporate a forward-looking theme for employees, refraining from looking back at past memories from firms that no longer exist or did not share the same principles of the acquiring firm. This particular concept would coincide with the servant leadership studies from Yigit and Bozkurt (2017), which suggested servant leaders look towards the 
future aim to embolden their followers to provide a constructive and helpful contribution to their organizations.

The research question for this study addressed how servant leadership principles impact employee turnover rates at an SWM firm. The results of the interviews and the analysis of the data generated through the interviews supported the concept that servant leadership has a positive influence on employee retention at an SWM firm. Several participants supportively endorsed servant leadership over other leadership models they had witnessed in other companies. Perhaps the most revealing aspect of the interviews concerning employee retention was that every participant confirmed, without hesitation, that the principles of servant leadership strongly influence their desire to remain with their current employer.

Each question in the interview questionnaire was intended to address the main research question for the study. Question 1 dealt with the participant's perception of the leadership practiced in their firm; many of the participants recognized that their firm specifically employed a servant leadership model. Question 2 tackled the impact servant leadership had on the participant personally and professionally; several participants indicated they integrated servant leadership seamlessly both at home and in the workplace. Question 3 asked what differentiated servant leadership from other leadership models they had seen in prior employers; comments such as "self-serving" and "bureaucratic" were used to describe other leadership models; "see it, say it" and "ego check" were applied to the current servant leadership philosophy used by their employer. Question 4 concentrated on the attributes of servant leadership that appealed to the participant; examples such as "the right thing to do," "removing barriers," "direct conversations," and "mentoring" were revealed by participants as positive servant leadership characteristics. Question 5 inquired as to how servant leadership worked in recruiting and retaining employees; "feeling appreciated," "awareness," and "reputation in the community" were a few of the ways the participants felt servant leadership worked in recruiting and retaining personnel. Question 6 examined whether or not servant leadership had an impact on a potential departure for the participant to a similar job in another firm that did not employ servant leadership; each participant unanimously concluded servant leadership is a key factor in their continued employment at their current employer. Finally, the last question allowed participants to add any additional remarks to the survey; comments like "great working for a company that believes in servant leadership," "We don't work for; we work with," and "they're having fun at work" were used to describe the participant's overall sentiments about the servant leadership used at their organization.

The findings through the interview process were not unexpected, as they supported the conclusions from the literature, as well as the experiences of the researcher. Many participants focused on the unique relationship between management and non-managers, in which the traditional hierarchal structure was not present. Servant leadership is distinctive in this respect amongst all other leadership styles; the horizontal focus is on followers, rather than a typical vertical leader-focused perspective (Williams et al., 2017). Also, servant leaders walk and move amongst their followers in a direction that can bond all in a common visualization (Boone \& Makhani, 2012).

Another point of emphasis from participants involved a team-first focus, along with team-based metrics, when evaluating results within the firm. Leaders have great influence over the members of a team and their remuneration, acknowledgment, and potential opportunities for development (McCarthy \& Milner, 2013). Boone and Makhani (2012) pointed to the ability of servant leaders to be cognizant that their successes originate from an attitude that spearheading organizational and group efforts leads to developing productive communities.

An unexpected finding, though not a trend or theme, involved the acknowledged commitment of time, funds, and human capital necessary in beginning or developing a servant leadership environment. One participant indicated that some of the best managers within the firm had to be terminated because of their refusal to integrate servant leadership, regardless of their financial success. Another participant was employed by the studied firm through an acquisition, indicating the prior company did not use a servant leadership model and that the change to servant leadership involved discomfort and considerable funds, but was well worth the efforts after witnessing the positive results. 
Several themes emerged from the data analysis in conjunction with those developed during the literature review:

1. Culture

2. Accountability

3. Support

4. Commitment

\section{Relationship of Themes to the Research Question}

Culture, accountability, support, and commitment are significant to how servant leadership principles impact employee turnover rates at an SWM firm. Every interview participant expressed a desire to remain with their current employer due to servant leadership principles, and most participants listed one or more of the aforementioned themes in describing their views on the firm and their leadership philosophies. Further, all of the themes identified were covered in the literature review for the study.

\section{Summary of the Findings}

The field study reaffirmed many of the aspects of leadership and, specifically, servant leadership initially discovered in the literature review for the report. The participants when referencing how leadership in their firm was executed mentioned the themes of culture, accountability, and support often. All of these themes helped to answer the research question on how servant leadership principles impact employee turnover rates at an SWM firm.

Additional topics were introduced by the participants during the interviews, but not to the level of an overall theme. Some participants volunteered subjects like care, creativity, trust, and value. Others mentioned relationships, training, and trust as factors that have contributed to their continued employment. A few ideas were mentioned by more than one participant that did not rise to the level of a theme, but were worthy of further discussion.

\section{APPLICATIONS TO PROFESSIONAL PRACTICE}

The current study examined the impact that servant leadership has on employee turnover in SWM firms. The results of the study were overwhelmingly positive towards a servant leadership philosophy practiced within an SWM firm. The literature strongly suggested firms that practice servant leadership adds significant value to their relations with employees (Barbuto \& Wheeler, 2006; Franscoise, 2016; Jit, Sharma, \& Kawatra, 2017; Guitierrez-Wirsching et al., 2015; Mertel \& Brill, 2015), and the interview participants confirmed the earlier findings of the literature re view. All of the participants viewed servant leadership as having a positive impact on their continued employment, identifying many of the aspects outlined in the literature review such as community building, listening, and growth. Other than the initial discomfort and growing pains associated with changing leadership models, none of the participants associated negative attributes towards the servant leadership demonstrated by their employer.

The consensus of the participants that servant leadership plays a critical factor in their continued employment convinced the researcher that a servant leadership model may work better than other leadership models in reducing turnover at SWM companies. Many authors reviewed for the study indicated the employee-driven needs of SWM firms (Cortinhal, Mourão \& Nunes, 2016; Sekerka \& Stimel, 2014; Baylor, 2016). Other authors pointed to the costs of employee turnover in general for firms (Wang et al., 2014; Zeng \& Honig, 2016; Spencer et al., 2016; Stormbroek \& Blomme, 2017). A leadership model like servant leadership that encourages significant investment in personnel and, in turn, discourages employee attrition, can be a valuable tool for SWM firms and other service industry companies to implement. The researcher concluded that an investment must ultimately be made in personnel by all firms: a servant leadership style encourages considerable investment in personnel immediately and continuing. Other leadership strategies often emphasize investing in recruiting replacement personnel only after employee separation has occurred. Servant leadership represents an 
effective long-term investment in both an organization and its personnel. Other models emphasize shortterm investments, often avoiding direct investment in the workforce.

The results of this study and the themes that emerged are unmistakably relevant to the use of servant leadership in SWM firms to help curtail employee turnover. SWM firms, according to Ghiani et al. (2014), must make various tactical, strategic, and operational choices, incorporating solid waste treatment options, treatment facility sites, capacity and expansion capabilities, the flow of waste and recyclables to treatment sites, operational service, waste and recyclable collection days, commercial fleet procurement and allocation, and the routing of all collection vehicles, all of which require substantial investments in personnel. Servant leadership should assist SWM firms in recruiting and retaining valued employees. The themes of culture, accountability, support, and commitment that materialized in the interviews from participants in a SWM firm that uses servant leadership reinforce the concepts that originated in the literature review and are replicable in not only other SWM firms, but other industries, as well.

The findings show a strong proclivity by many towards a servant leadership model over other leadership models. Servant leadership shares many qualities with other modern leadership models, such as transformational leadership and situational leadership. The conspicuous difference between servant leadership and other leadership types is the well-defined focus on others first and foremost. Servant leadership posits the leader serves and serves first, making those who follow become healthier, freer, and more autonomous (Greenleaf, 1977). The trend of servant leadership is growing in stature and is manifesting in many industries outside of SWM. The researcher is confident the findings of this study will not only help to contribute towards leadership in general, but specifically in the SWM industry in which firms are frequently looking for an edge in recruiting and retaining high quality employees.

\section{Recommendations for Further Study}

Given the time frame for data collection, a limitation of the study was the sample size itself. Also, given the proprietary nature of private businesses, the questions asked to participants could not go into greater detail as to the particular aspects of servant leadership and how they are used in the case study SWM firm. The study, nor the literature, directly addressed the consequences of employees within SWM firms who did not adhere to servant leadership principles. The following recommendations are suggested for future researchers.

\section{Broaden the Sample Size}

Though saturation was reached in this study, a more nuanced view of servant leadership may be accessible if a study were segmented by location, division, or occupation, as opposed to job status, tenure, and whether or not the participants had former employers.

\section{Expand the Market}

The number of SWM firms that use a servant leadership philosophy was limited, according to the literature. A more expansive view of servant leadership may be available if other service-intensive industries that used a servant leadership model were included in a study.

\section{Employee Separation}

Researchers should investigate the processes in place for terminating employees who did not meet the servant leadership standards in SWM firms. Further, what procedures must be established, given the lack of consensus, clear definition, or theoretical framework behind servant leadership (Davenport, 2015), to warrant terminating an employee?

This study focused on the impact servant leadership has on employee retention efforts at SWM firms. The researcher hopes future studies can utilize the information outlined in this study for future considerations on related topics. 


\section{Summary and Study Conclusions}

This study focused on the impact servant leadership had on employee turnover at an SWM firm. The researcher concentrated on servant leadership due to the trend of companies using this evolving leadership model, the SWM market based on the researcher's industry experience, and employee turnover as a critical issue for every firm that employs individuals. The researcher conducted a series of interviews for the study, with the data analysis creating multiple themes to support the findings. The findings suggested servant leadership played a critical role in retaining employees through the themes of culture, accountability, support, and commitment as expressed by the research participants.

Many different leadership styles were researched for the study, and the literature suggested a strong preference by employees for servant leadership models to be used in their vocations. The literature researched for this study on employees and costs of employee turnover suggested a balance from employers between tangible and intangible rewards helped in retention efforts. The SWM industry was also researched, with little information available on leadership models practiced by SWM firms and their effectiveness in reducing employee turnover.

The study was conducted using participants from various locations of an SWM firm that uses servant leadership, all of which had at least 6 months of continuous full-time employment with the researched firm, as well as at least one previous employer to gauge the servant leadership management model against. Interviews were structured based on the concepts derived from the literature on leadership, servant leadership, SWM, and employee turnover. The phone interviews were semi-structured, recorded, and transcribed for the intentions of coding and data analysis.

The research conducted for this study may assist in closing the gap in literature concerning servant leadership and its direct impact on employee retention in the SWM industry. SWM firms require significant investment into personnel through training, licensure for operating commercial vehicles, and competitive remuneration. A leadership theory that potentially diminishes employee turnover. Strengthening personnel matters is worth further investigation by any SWM firm.

The findings of the study suggested a strong relationship between servant leadership, employee satisfaction, and employee retention efforts. SWM firms, as well as other service-intensive organizations, may be drawn to the impact servant leadership philosophies have on the employees within the SWM firm based on the results of the study. An investment into SWM personnel now in the form of servant leadership and its attributes may pay greater dividends in the forms of reduced turnover, increased satisfaction, and higher profits.

\section{REFERENCES}

Akbari, M., Kashani, S. H., Nikookar, H., \& Ghaemi, J. (2014). Servant leadership and organizational identity: The mediating role of job involvement. International Journal of Organizational Leadership, 3(2), 41-55.

Antunes, A., \& Franco, M. (2016). How people in organizations make sense of responsible leadership practices: Multiple case studies. Leadership \& Organizational Development Journal, 37(1), 126152. doi: 10.1108/LODJ-04-2014-0084

Auvinen, T. P., Lämsä, A. M., Sintonen, T., \& Takala, T. (2013). Leadership manipulation and ethics in storytelling. Journal of Business Ethics, 116(2), 415-431. doi: 10.1007/s10551-012-1454-8

Barbuto Jr., J. E., \& Gottfredson, R. K. (2016). Human capital, the millennial's reign, and the need for servant leadership. Journal of Leadership Studies, 10(2), 59-63. doi: 10.1002/j1s.21474

Barbuto Jr., J. E., \& Wheeler, D. W. (2006). Scale development and construct clarification of servant leadership. Group \& Organization Management, 31(3), 300-326. doi: $10.1177 / 1059601106287091$

Baylor, K. M. (2016, Aug. 4). The influence of bad habits and solid waste industry myths on safety performance. Waste360 (Online), 1-5.

Boddy, C. R. (2016). Sample size for qualitative research. Qualitative Market research: An International Journal, 19(4), 426-432. doi: 10.1108/QMR-06-2016-0053 
Boone, L. W., \& Makhani, S. (2012). Five necessary attitudes of a servant leader. Review of Business, 33(1), 83-96.

Chan, S. C. H., \& Mak, W (2013). The impact of servant leadership and subordinates' organizational tenure on trust in leader and attitudes. Personnel Review, 43(2), 272-287. doi: 10.1108/PR-082011-0125

Cortinhal, M. J., Mourão, M. C., \& Nunes, A. C. (2016). Local search heuristics for sectoring routing in a household waste collection context. European Journal of Operational Research, 255(1), 68-79. doi: 10.1016/j.ejor.2016.04.013

Creswell, J. W., \& Poth, C. N. (2018). Qualitative inquiry \& research design: Choosing among five approaches $\left(4^{\text {th }}\right.$ ed.). Thousand Oaks, CA: Sage.

Davenport, B. (2015). Compassion, suffering and servant-leadership: Combining compassion and servant-leadership to respond to suffering. Leadership, 11(3), 300-315. doi: $10.1177 / 1742715014532481$

de Souza Melare, A. V., Gonzalez, S. M., Faceli, K., \& Casadei, V. (2017). Technologies and decision support systems to aid solid-waste management: A systematic review. Waste Management, 59, 567-584. doi: 10.1016/j.wasman.2016.10.045

Devi, Y. U., \& Krishna, V. M. (2016). Impact of human resources management practices on employee turnover- an empirical study with special reference to IT sector. Journal of Strategic Human Resource Management, 5(3), 50-54.

DeWeese, A. (1999). Turning around driver turnover. Waste Age, 30(7), 10-12.

Dutta, S., \& Khatrri, P. (2017). Servant leadership and positive organizational behaviour: The road ahead to reduce employees' turnover intentions. On the Horizon, 25(1), 60-82. doi: 10.1108/OTH-062016-0029

Fickes, M. (2011). The path less taken. Waste Age Exclusive Insight, 8.

Flint, D., Haley, L. M., \& McNally, J. J. (2013). Individual and organizational determinants of turnover intent. Personnel Review, 42(5), 552-572. doi: 10.1108/PR-03-2012-0051

Franscoise, C. T. (2016). Servant and spiritual leadership theories: Are they two different notions? Journal of Human Values, 22(3), 202-208. doi: 10.1177/0971685816650578

Ghiani, G., Lagana, D., Manni, E., Musmanno, R., \& Vigo, D. (2014). Operations research in solid waste management: A survey of strategic and tactical issues. Computers \& Operations Research, 44, 22-32. doi: 10.1016/j.cor.2013.10.006

Graen, G. B., \& Uhl-Bien, M. (1995). Relationship-based approach to leadership: Development of leadermember exchange (LMX) theory of leadership over 25 years: Applying a multi-level multidomain perspective. The Leadership Quarterly, 6(2), 219-247. doi: 10.1016/10489843(95)90036-5

Greenleaf, R. (1977). Servant leadership: A journey into the nature of legitimate power \& greatness. Mahwah, NJ: Paulist Press.

Greenwalt, M. (2017, Sept. 19). Waste Management exploring use of autonomous vehicles at landfills, MRFs. Waste360 (Online), 1-2.

Guitierrez-Wirsching, S., Mayfield, J., Mayfield, M., \& Wang, W. (2015). Motivating language as a mediator between servant leadership and employee outcomes. Management Research Review, 38(12), 1234-1250. doi: 10.1108/MRR-01-2014-0009

Hancock, J. I., Allen, D. G., Bosco, F. A., McDaniel, K. R., \& Pierce, C. A. (2013). Meta-analytic review of employee turnover as a predictor of firm performance. Journal of Management, 39(3), 573603. doi: $10.1177 / 0149206311424943$

Harvey, C. (2017). The intricate process of psychoanalytic research: Encountering the intersubjective experience of the researcher-participant relationship. British Journal of Psychotherapy, 33(3), 312-327. doi: 10.1111/bjp.12282

Hausknecht, J. P. (2017). Collective turnover. The Annual Review of Organizational Psychology and Organizational Behavior, 4(1), 527-544. doi: 10.1146/annurev-orgpsych-032516-113139 
Hersey, P., \& Blanchard, K. H. (1982). Management of organizational behavior: Utilizing human resources $\left(4^{\text {th }}\right.$ ed.). Englewood Cliffs, NJ: Prentice-Hall.

Herzberg, F. (1974). Motivation-hygiene profiles: Pinpointing what ails the organization. Organizational Dynamics, 3(2), 18-29. doi: 10.1016/0090-2616(74)90007-2

Jalil, E. E. A., Grant, D. B., Nicholson, J. D., \& Deutz, P. (2016). Reverse logistics in household recycling and waste systems: A symbiosis perspective. Supply Chain Management: An International Journal, 21(2), 245-258. doi: 10.1108/SCM-02-2015-0056

Jaunich, M. K., Levis, J. W., DeCarolis, J. F., Gaston, E. V., Barlaz, M. A., Bartelt-Hunt, S. L., ... \& Jaikumar, R. (2016). Characterization of municipal solid waste collection operations. Resources, Conservation, and Recycling, 114, 92-102. doi: 10.1016/j.resconrec.2016.07.012

Jit, R., Sharma, C. S., \& Kawatra, M. (2016). Servant leadership and conflict resolution: A qualitative study. International Journal of Conflict Management, 27(4), 591-612. doi: 10.1108/IJCMA-122015-0086

Jit, R., Sharma, C. S., \& Kawatra, M. (2017). Healing of a broken spirit: Role of servant leadership. The Journal for Decision Makers, 42(2), 80-94. doi: 10.1177/0256090917703754

Kashyap, V., \& Rangnekar, S. (2016). Servant leadership, employee brand perception, trust in leaders and turnover intentions: A sequential mediation model. Review of Managerial Science, 10(3), 437461. doi: 10.1007/s11846-014-0152-6

Kirakozian, A. (2016). One without the other? Behavioural and incentive policies for household waste management. Journal of Economic Surveys, 30(3), 526-551. doi: 10.1111/joes.12159

Krog, C. L., \& Govender, K. (2015). The relationship between servant leadership and employee empowerment, commitment, trust and innovative behaviour: A project management perspective. SA Journal of Human Resource Management, 13(1), 1-12. doi: 10.4102/sajhrm.v13i1.712

Lacey, R., \& Kennett-Hensel, P. A. (2015). Is corporate social responsibility a motivator or hygiene factor? Insights into its bivalent nature. Academy of Marketing Science Journal, 43(3), 315-332. doi: $10.1007 / \mathrm{s} 11747-014-0390-9$

Lacroix, M., \& Verdorfer, A. P. (2017). Can servant leaders fuel the leadership fire? The relationship between servant leadership and followers' leadership avoidance. Administrative Sciences, 7(1), 617. doi: 10.3390/admsci7010006

Lapointe, E., \& Vandenberghe, C. (2018). Examination of the relationships between servant leadership, organizational commitment, and voice and antisocial behaviors. Journal of Business Ethics, 148, 99-115. doi: 10.1007/s10551-015-3002-9

Mahembe, B., \& Engelbrecht, A. S. (2014). The relationship between servant leadership, organisational citizenship behaviour and team effectiveness. SA Journal of Industrial Psychology, 40(1), 1-10. doi: 10.4102/sajip.v40i1.1107

Maslow, A. H. (1998). Maslow on management. Hoboken, NJ: John Wiley \& Sons.

McCarthy, G., \& Milner, J. (2013). Managerial coaching: Challenges, opportunities, and training. Journal of Management Development, 32(7), 768-779. doi: 10.1108/JMD-11-2011-0113

Mertel, T., \& Brill, C. (2015). What every leader ought to know about becoming a servant leader. Industrial and Commercial Training, 47(5), 228-235. doi: 10.1108/CT-02-2015-0013

Nasidi, Y., Kamarudeen, A. M., \& Bahaudin, Y. (2015). Relationship between transformational leadership and construction waste material recycling among construction organizations. International Journal of Management Research and Reviews, 5(12), 1187-1194.

O’Reilly, M., \& Parker, N. (2012). 'Unsatisfactory saturation': A critical exploration of the notion of saturated sample sizes in qualitative research. Qualitative Research, 13(2), 190-197. doi: $10.1177 / 1468794112446106$

Otero-Neira, C., Varela-Neira, C., \& Bande, B. (2016). Supervisory servant leadership and employee's work performance: A multilevel mediation model. Leadership \& Organizational Development Journal, 37(7), 860-881. doi: 10.1108/LODJ-11-2014-0230 
Parris, D. L., \& Peachey, J. W. (2013). A systematic literature review of servant leadership theory in organizational contexts. Journal of Business Ethics, 113, 377-393. doi: 10.1007/s10551-0121322-6

Reina, C. S., Rogers, K. M., Peterson, S. J., Byron, K., \& Hom, P. W. (2018). Quitting the boss? The role of manager influence tactics and employee emotional engagement in voluntary turnover. Organizational Studies, 25(1), 5-18. doi: 10.1177/1548051817709007

Searle, T. P., \& Barbuto Jr, J. E. (2013). A multilevel framework: Expanding and bridging micro and macro levels of positive behavior with leadership. Journal of Leadership \& Organizational Studies, 20(3), 274-286. doi: 10.1177/1548051813485133

Sekerka, L. E., \& Stimel, D. (2014). Embracing waste as a resource: Insights from the informal sector. Management Research Review, 37(3), 241-260. doi: 10.1108/MRR-11-2012-0254

Sendjaya, S., Sarros, J. C., \& Santora, J. C. (2008). Defining and measuring servant leadership behaviour in organizations. Journal of Management Studies, 45(2), 402-424. doi: 10.1111/j.14676486.2007.00761.x

Sersland, D., \& Nataraajan, R. (2015). Driver turnover research: Exploring the missing angle with a global perspective. Journal of Service Management, 26(4), 648-661. doi: 10.1108/JOSM-042015-0129

Shuck, B., Twyford, D., Reio Jr., T. G., \& Shuck, A. (2014). Human resource development practices and employee engagement: Examining the connection with employee turnover intentions. Human Resource Development Quarterly, 25(2), 239-270. doi: 10.1002/hrdq.21190

Stake, R. E. (2010). Qualitative research: Studying how things work. New York, NY: The Guilford Press.

Tsang, E. W. K. (2014). Generalizing from research findings: The merits of case studies. International Journal of Management Reviews, 16, 369-383. doi: 10.1111/ijmr.12024

Vault (2019) Waste management. Retrieved from http://www.vault.com/industriesprofessions/industries/waste-management.aspx.

Wang, X., Wang, L., Xu, X., \& Ji, P. (2014). Identifying employee turnover risks using modified quality function deployment. Systems Research and Behavioral Science, 31, 398-404. doi: $10.1002 /$ sres. 2282

Williams Jr., W. A., Brandon, R. S., Hayek, M., Haden, S. P., \& Atinc, G. (2017). Servant leadership and followership creativity: The influence of workplace spirituality and political skill. Leadership \& Organizational Development, 38(2), 178-193. doi: 10.1108/LODJ-02-2015-0019

Wilson, D. C., \& Velis, C. A. (2014). Cities and waste: Current and emerging issues. Waste Management \& Research, 32(9), 797-799. doi: 10.1177/0734242X14547125

Yigit, B., \& Bozkurt, S. (2017). A content analysis of servant leadership studies. International Journal of Organizational Leadership, 6(2), 190-196. doi: 10.19236/IJOL.2017.02.04

Yin, R. K. (2014). Case study research: Design and methods (5 $5^{\text {th }}$ ed.). Thousand Oaks, CA: Sage

Zeng, Z., \& Honig, B. (2016). A study of living wage effects on employees' performance-related attitudes and behaviour. Canadian Journal of Administrative Sciences, 34, 19-32. doi: 10.1002/CJAS.1375 